with Social Phobia as an Empirically Grounded Clinical Intervention

D.J.A. Edwards

Pragmatic Case Studies in Psychotherapy, http://pcsp.libraries.rutgers.edu

Volume 2, Module 1, Article 6, pp. 1-17, 02-17-06 [copyright by author]

Response to Commentaries on Identifying and Targeting Idiosyncratic Cognitive Processes in Group Therapy for Social Phobia: The Case of Vumile

\title{
How the Case of Vumile Contributes to the Evidence Base for Cognitive Therapy with Social Phobia as an Empirically Grounded Clinical Intervention
}

\section{DAVID J.A. EDWARDS ${ }^{\mathrm{a}, \mathrm{b}}$}

\author{
${ }^{a}$ Rhodes University, South Africa \\ ${ }^{\mathrm{b}}$ Correspondence concerning this article should be addressed to David J.A. Edwards, Department of \\ Psychology, Rhodes University, Grahamstown, 6140, South Africa \\ Email: mailto:D.Edwards@ru.ac.za
}

\begin{abstract}
This article is a response to commentaries by Davison (2005), S. Fishman (2006), Sanderson (2006), and Turk (2006) on Edwards and Kannan's (2006) case study, which documents the response to group therapy of Vumile, a South African student with social phobia. The case material is discussed in relation to five themes raised by the commentators: (a) the tension between structure and flexibility in manualization of treatments, (b) theoretical and practical aspects of the planning and implementation of the intervention, (c) the adaptation of an individual treatment to a group therapy format, (d) methodological aspects of data collection, and (e) methodological aspects related to the drawing of conclusions from the case material. Broader implications are drawn for the place of case-based methodology in the development of evidence-based practice in psychotherapy.
\end{abstract}

Key words: case study methodology; cognitive therapy; evidence-based practice; manualized treatment; social phobia

S. Fishman (2006), Sanderson (2006), and Turk (2006), the authors of the commentary papers in this module, as well as Davison (2005), one of the reviewers of the paper for this journal, made several pertinent comments on the case study of Vumile, a participant in a group therapy program for social phobia (Edwards \& Kannan, 2006). The comments can be grouped thematically into five areas which have been used to organize the present response.

\section{THE TENSION BETWEEN A STRUCTURED, MANUALIZED APPROACH AND ATTENTION TO INDIVIDUAL CASE FORMULATION}

Sanderson (2006) and Turk (2006) both discuss the conflict between (a) the development of prescriptive treatment manuals which set out precise steps and strategies in a 
How the Case of Vumile Contributes to the Evidence Base for Cognitive Therapy

with Social Phobia as an Empirically Grounded Clinical Intervention

D.J.A. Edwards

Pragmatic Case Studies in Psychotherapy, http://pcsp.libraries.rutgers.edu

Volume 2, Module 1, Article 6, pp. 1-17, 02-17-06 [copyright by author]

pre-determined order, and (b) the development of treatments that are organized around more general principles and use case formulation as a basis for determining what interventions to make at any given time. Positions taken on this issue could be arranged on a continuum with, at each end, an apparently polar opposite: a prescriptive pole characterized by insistence that set steps and interventions must be implemented in a fixed order, and a formulation-driven pole whose proponents emphasize the need to work flexibly and interactively with the unique features of each individual case (e.g. Persons, 1989; Persons \& Tomkins, 1997). This reflects a broader tension within our discipline between the need to find general laws or formulas and the need to respect the uniqueness of the person. These contrasting agendas were already being discussed by researchers on personality using the terms "nomothetic" and "idiographic" a century ago (Allport, 1963). The conflict between them is particularly pertinent to psychotherapy outcome research where critics have expressed concern that the recent focus on terms like "empirically supported treatments" (ESTs) and "evidence-based practice" (EBP) has led to excessive emphasis on the nomothetic pole, with a corresponding neglect of factors which reflect unique characteristics of the therapy situation, the interpersonal relationship between client and therapist, the personal attributes of the therapist, and the experience of the client (Wampold \& Bhati, 2004; Messer, 2004).

The term "manualization" is often taken to indicate an approach at or close to the prescriptive pole. Thus, Petronko (2005, p. 2), commenting on an earlier case study in this journal, wrote, "the degree of manualization that leads to optimal outcome effectiveness is itself an empirical question." However, increasingly there are researchers (who include Sanderson and Turk) who are articulating principles and guidelines for a middle ground within which the strengths at each pole can be preserved and held in balance and who use the term "manualized treatment" to refer to approaches which combine prescription with flexibility. Treatment flexibility means having a manual which does not prescribe step by step or even session by session, but allows the treatment to unfold in a manner that is formulation driven. For example, Persons and Tomkins (1997, p. 337) suggest that "protocol treatment and individualized treatment might be combined by using standardized components as the building blocks for individual treatments." I am currently working with Ehlers and Clark's research group, who are developing a manualized treatment for PTSD (Ehlers, Clark, Hackmann, McManus, \& Fennell, 2005). This kind of flexibility is a hallmark of the manual they are developing, and there is considerable tolerance of co-morbidity in research trials (Ehlers, personal communication, August 2005).

As the debate becomes more refined, a consensus seems to be emerging about the nature of that middle ground. This consensus draws heavily on data from cases where experience is gained in applying principles in practice. A great deal of clinical knowledge emerges from everyday clinical practice when therapists discuss their cases with supervisors or colleagues, and such supervision processes contribute indirectly to the development of scientific knowledge. This kind of supervision is also a major feature of the development work that goes into research on treatment manuals, but this aspect of the process is often not made public. The development of scientific knowledge is a public project and its processes must be open to inspection by all involved. The publication of systematic, peer-reviewed case studies of the type found in this PCSP journal therefore allows the informal clinical process to become an explicit part of the public domain of knowledge development, that is, such publication helps to place the holistic and naturalistic conduct of therapy under scientific 
How the Case of Vumile Contributes to the Evidence Base for Cognitive Therapy

with Social Phobia as an Empirically Grounded Clinical Intervention

D.J.A. Edwards

Pragmatic Case Studies in Psychotherapy, http://pcsp.libraries.rutgers.edu

Volume 2, Module 1, Article 6, pp. 1-17, 02-17-06 [copyright by author]

investigation (Edwards, Dattilio, \& Bromley, 2004; D. Fishman, 2005).

The Vumile case arose out of a study that was conceptualized from this middle ground, even though, when the research was conducted in 2000, there was much less consensus about whether a resolution could be achieved. The significance of such cases studies for this debate is highlighted by Sanderson and Turk. Turk (2006) remarks how "I often wonder how far one can push the envelope in terms of manualized treatments" and shows how a case study can contribute to a scientific examination of such questions. She also examines how this tension is practically resolved in the Vumile case, which, she concludes provides evidence that "manualized treatments are not just a set of procedures applied in a blanket fashion to each patient irrespective of individual characteristics and needs."

Sanderson (2006) also articulates the importance of "striking a balance" and points out how manualization can lead to inflexibity in dealing with co-morbidity as well in identifying and responding appropriately to obstacles to treatment progress. With this in mind, he interrogates the Vumile narrative "to identify the coordination of adherence and flexibility" and examine "where one was sacrificed for the other." He raises two questions with respect to co-morbidity. First, might Vumile also have had post-traumatic stress disorder (PTSD). This seems unlikely since although this diagnosis might have eluded our initial screening, it is improbable that it would not have emerged during the extended assessment that took place in the early sessions, during which participants investigated and reported back on the nature and context of anxiety episodes in some detail. Similarly, as the program continued, if Vumile had had significant concerns about being physically or emotionally abused, these would surely have come to light. Nevertheless, as Turk (2006) points out, even without a diagnosis of PTSD, traumatic events such as being bullied can play a role in predisposing individuals to social phobia, and the kind of processes that maintain PTSD can play a role in social phobia too. Clark and Wells' cognitive therapy for social phobia (CTSP) can easily be extended to incorporate this kind of new information. For example, Clark's research group has recently reported (Wild, Hackmann, Clark, \& Ehlers, $2005)$ on the incorporation into their social phobia treatment of "imagery rescripting," that is, the cognitive reworking of anxiety-laden images in memory.) This intervention was initially developed for PTSD and related syndromes associated with sexual and physical abuse in childhood (Smucker \& Dancu, 1999).

Sanderson also raises concerns about co-morbidity with depression. There are several reasons why the Clark manual can cater for depression as well as social phobia. First, in social phobics, depression may largely be centered on disappointment and loss because of the absence of meaningful relationships, and on hopelessness about overcoming this problem. Addressing the social phobia can thus address some of the main factors maintaining the depression. Second, the social phobia manual includes many standard cognitive interventions that are useful for identifying and dealing with dysfunctional thinking patterns of all sorts. Indeed, as Watkins, Mansell and Shafran (2004) show, because there is some commonality in the cognitive mechanisms that maintain different disorders, there are many interventions that can be helpful in social phobia, PTSD and depression. Third, avoidance associated with social anxiety and avoidance related to depression both have the effect of undermining the client's motivation to actively work in treatment. Here the therapist's task is to work with interventions which enhance motivation. All three of these factors apply in Vumile's case. 
How the Case of Vumile Contributes to the Evidence Base for Cognitive Therapy

with Social Phobia as an Empirically Grounded Clinical Intervention

D.J.A. Edwards

Pragmatic Case Studies in Psychotherapy, http://pcsp.libraries.rutgers.edu

Volume 2, Module 1, Article 6, pp. 1-17, 02-17-06 [copyright by author]

Since our study was conducted, there has been increasing recognition that the strategy of delivering manualized treatments narrowly targeted at specific DSM-IV disorders has its limitations due to the frequency with which co-morbidity is encountered in clinical practice, and the commonality across different disorders of the cognitive mechanisms that maintain them (Harvey, Borkovec, Hayes, Persons, \& Wilson, 2005; Watkins, Mansell, \& Shafran, 2004). Thus, many interventions can be helpful in treating social phobia, PTSD and depression and, as already indicated, the Clark manual for social phobia can be used and further developed in a flexible manner in light of this.

When treatment is offered in a group, there are further constraints on responsiveness to the needs of each individual. In CTSP, if group leaders spend time on participants who had significant PTSD or disabling depression, it might detract from offering optimal treatment to other participants. The problem here is not so much one of flexibility or lack of it but finding a way of meeting the competing needs among a group of participants. This is why cognitive-behavioral group therapy is regularly offered to groups of participants with fairly homogenous presenting problems (White \& Freeman, 2000). The question of just how much diversity of presenting symptomatology there can be before it becomes counterproductive needs to be examined empirically, and a case-based program evaluation strategy such as the one used in the present study could be valuable for this purpose.

Sanderson (2006) raises a third concern about inflexibility when he suggests that, given Vumile's slow response to the intervention, we might have acted earlier to develop a more targeted intervention rather than doing "more of the same." However, "more of the same" is not an accurate characterization of the treatment approach since (a) new perspectives and strategies for tackling social phobia continue to be introduced up until the last few sessions, and (b) there is an ongoing emphasis on participants conducting an ever deepening investigation of the factors maintaining their social phobia through self-monitoring and behavioral experiments. Although the full significance of Vumile's projection of disdainful facial expressions on to women who were in close proximity to him was only recognized in the last session, had it been recognized earlier there is nothing in the principles behind our approach that would have prevented us from addressing it. This projective imaging had not yielded to logical analysis and rational evaluation of the belief "they are looking at me with pity and disdain." It was Vumile's behavioral experiment in which he systematically observed women's faces that altered it. It is probable that the behavioral experiment might have had the same impact earlier had he or the group leaders thought of it. But it was not slavish adherence to the manual that prevented this. The idea that behavioral experiments could serve as a means of testing out dysfunctional beliefs was introduced as early as session 4 and more explicitly addressed in session 7 where participants were given the "Record sheet for noting behavioral experiments" and encouraged to use it in practice.

There are three other factors that could explain why Vumile's projection of disdainful facial expressions on to women was not addressed earlier. The first is simply that in Vumile's case there was a range of interacting factors maintaining the social phobia and it took time to tease them out and tackle each of them. The second is that this particular process has not been widely described in the social phobia literature and was not explicitly addressed in the manual. Therefore the group leaders were not sensitized to it. At the time of the study the role of negative self-images was well understood and a great deal of attention 
How the Case of Vumile Contributes to the Evidence Base for Cognitive Therapy

with Social Phobia as an Empirically Grounded Clinical Intervention

D.J.A. Edwards

Pragmatic Case Studies in Psychotherapy, http://pcsp.libraries.rutgers.edu

Volume 2, Module 1, Article 6, pp. 1-17, 02-17-06 [copyright by author]

was directed at identifying and addressing these. This kind of projective imaging has still not been widely described, and one of the contributions of a case study like this is to point to the need for further research in this area. The third factor that may have played a role is that the projective imaging process eluded detection because the attention of the group leaders was somewhat stretched by tracking the processes of five participants. Perhaps this process might have been picked up earlier in individual therapy. Even though the Vumile study shows that one can tailor an individual treatment within a group program, it is clearly a disadvantage of group therapy that less attention is paid to the individual. To some extent, of course, this is offset by the many advantages of the group situation that are discussed by Edwards and Kannan (2006).

\section{THE CONCEPTUALIZATION, PLANNING AND IMPLEMENTATION OF THE INTERVENTION}

The commentators raised several questions about practical aspects of the intervention itself. Thus S. Fishman (2006) doubts whether safety behaviors, being so automatic and habitual, can simply be dropped in response to an instruction from the therapist. In practice the instruction to drop them during the safety behaviors experiment (SBE) was sufficient for all the other participants in our program - as well as participants in treatment and research by Clark's group (Bates and Clark, 1998; McManus, et al, 2005). However, in CTSP, this instruction does not come out of the blue. In the Edwards and Kannan (2006) program, participants had already received psychoeducation about the role of safety behaviors, had identified and monitored many of their own, and had seen other group members doing the same. In preparation for the SBE they were asked to list their safety behaviors once again. This does not mean that after this safety behaviors ceased to be a problem. Vumile's selfratings of safety behaviors in everyday social contexts did not change until very late in the program. Thus, under conscious control, participants can drop safety behaviors in the SBE, but this is not the same as learning to do without them on a habitual basis. In achieving this goal, more than practice seems to be involved. The change occurred for Vumile when he could see he did not need them because social situations were not actually as threatening as they had seemed under the influence of his images of disdainful and pitying faces looking at him. For other participants, including the case described by Bates and Clark (1998), this shift occurred much earlier.

Davison and S. Fishman both commented on Clark's view that relaxation training can serve to add another safety behavior to the client's repertoire and thus be counterproductive for outcome. Although, at times, it may be difficult to differentiate a safety behavior from an adaptive coping strategy, this can be achieved by a careful examination of the function of the behavior for the individual concerned (Thwaites \& Freeston, 2005). The Clark and Wells approach to social phobia is unusual in that it does not include a formal relaxation training component. Clark would argue that in order to overcome social phobia individuals need to learn to (a) tolerate anxiety, (b) keep attention on task and off the anxiety, (c) recognize that the anxiety is not significantly noticeable to others, (d) learn that being anxious does not mean that there is something wrong with them, and (e) learn that they can perform effectively in its presence. Each of these goals can be achieved by cognitive restructuring and behavioral experiments, while relaxation training and applied relaxation practice can fail to address these 
How the Case of Vumile Contributes to the Evidence Base for Cognitive Therapy

with Social Phobia as an Empirically Grounded Clinical Intervention

D.J.A. Edwards

Pragmatic Case Studies in Psychotherapy, http://pcsp.libraries.rutgers.edu

Volume 2, Module 1, Article 6, pp. 1-17, 02-17-06 [copyright by author]

goals or might even undermine them. In a recent randomized controlled trial, Clark et al (2005) reported a strong effect size of 1.46 for an exposure and applied relaxation intervention, but a much larger one of 2.63 for CTSP. This superiority of CTSP supports Clark's claim.

S. Fishman (2006) observed that many interventions used with Vumile are the same as those used in social skills training interventions, for example by the Heimberg group. He therefore questions the claim that the social phobic usually does not need to learn social skills. This claim is not meant to imply that there is no value in practicing new ways of relating in role play and in vivo. It is making a more specific point that most social phobics do not suffer from a skills deficit. They often have an adequate repertoire of social skills that they can draw on if they can break the maladaptive avoidance habits that interfere with the exercise of those skills. This means that in the Clark and Wells model practice situations are reframed as contexts in which participants can both (a) disconfirm dysfunctional beliefs, and (b) learn to give up safety behaviors so that they can access an experience of spontaneity and trust their own responsiveness to carry them through the unfolding process of social interaction. This responsiveness includes an available repertoire of social behaviors. Thinking of it in this way, rather than as social skills training, focuses the attention of the therapist (and client) on the change processes that, in terms of the model, are most significant.

Sanderson and Turk noticed that nothing was said in the narrative about whether the treatment needed to be modified in work with black African students. The absence of any comment on culture does not reflect a lack of sensitivity to culture on our part. Among Africans attribution of symptoms to witchcraft is a common obstacle to recovery and can complicate treatment for conditions such as PTSD (Eagle, 2004) or the chronic fatigue-like syndrome called "brain fag" (Ensink \& Robertson, 1997). With a less educated group, and especially in a rural context where African traditions predominate, it is likely that cultural factors would also play a role in a treatment that focused on social relations. However, the concerns of the participants in our group largely reflected the developmental and occupational contexts of their lives as young, single students who were lonely and socially isolated and were seeking to engage more widely in social interaction, make meaningful friendships and pursue intimacy. Our familiarity with the lives of students enabled us to understand the everyday situations with which they worked in the program, and there were no obvious cultural factors which surprised us or called for us to modify the basic treatment approach.

Davison made several comments on Clark and Wells' conceptualization of the assessment and treatment process. He wondered whether underlying beliefs are viewed from the perspectives of Beck and Ellis, the founding fathers of cognitive therapy. He pointed out that for Beck beliefs are a matter of empirical fact that can be challenged by reality testing. For Ellis they are more like values that cannot be dislodged by reference to reality but need to be challenged by ideological persuasion. From this perspective, the roots of the Clark and Wells approach are in the Beckian tradition. Most of the dysfunctional beliefs that are identified as contributing to the social phobia are targeted by reality testing. However, this is achieved by a wide range of active strategies. It is important to recognize the functional and dynamic nature of the Clark and Wells model in terms of which self-consciousness and the accompanying anxiety and withdrawal are created by the interaction of a variety of factors, 
How the Case of Vumile Contributes to the Evidence Base for Cognitive Therapy

with Social Phobia as an Empirically Grounded Clinical Intervention

D.J.A. Edwards

Pragmatic Case Studies in Psychotherapy, http://pcsp.libraries.rutgers.edu

Volume 2, Module 1, Article 6, pp. 1-17, 02-17-06 [copyright by author]

including: experiences of anxiety symptoms; thoughts and beliefs (including assumptions, attributions, negative predictions); images (e.g., of the self as unattractive or freezing up); anticipatory or postmortem worrying; and safety behaviors. Although cognitive change is a central feature of the model, an ever widening range of strategies is used to promote this: from rational analysis, to pointing out the self-defeating nature of specific beliefs, to even persuasively suggesting that certain beliefs are wrong or unhelpful, to providing feedback from a neutral party in the safety behaviors role play, to observing and reflecting on the video of that role play, and to devising behavioral experiments in real life situations.

Davison comments that "Ellis would say: 'So what if people think I am uninteresting?" For Clark, however, this misses the important point that the client is creating $\mathrm{him} /$ herself as an uninteresting person through the exercise of safety behaviors. It is probable that, without them, the client can and will be interesting to others. Behavioral experiments are specifically structured to bring negative predictions to awareness and test them in a systematic manner. Through them, "guided discovery" takes on a new meaning. It is not achieved merely through reflection on what has already taken place in the normal course of things. Critical events are actively created to provide evidence which can be examined later. As part of this, clients may need to be prepared for setbacks and disappointments and may need the therapist's help in interpreting them in a constructive manner. As Davison observes, when behavioral experiments are undertaken, "the therapist cannot control what happens in the patient's own world. The behavior of the people the patient interacts with cannot be controlled or perfectly predicted." The approach is thus radically empirical.

Davison also observes how Clark and Wells' program builds on the work of important earlier theorists. Bandura's (1977) reciprocal interaction model of social learning is implicit in the approach to formulation, and the program incorporates tried and tested cognitivebehavioral methods such as identification of dysfunctional thoughts and challenging them with the dysfunctional thought record, introduced by Beck (Beck, Rush, Shaw and Emery, 1979); self-instructional training, introduced by Meichenbaum (1977); and relapse prevention strategies, introduced and elaborated by Marlatt in the field of substance dependency and abuse (Marlatt \& Gordon, 1984). Not all of these are reflected in a single case narrative, but the way in which traditional components are mixed with new ones can be judged from the complete program as it appears in the Appendix of the Vumile paper.

\section{THE ADAPTATION OF THE CTSP MANUAL INTO A GROUP THERAPY FORMAT}

Turk raises several questions about our adaptation of the Clark manual for CTSP into a group therapy format. Our case-based evaluation allows us to conclude that CTSP can be effectively delivered in a group format. At least two other group versions of CTSP have been reported, both of which differ from ours in that the safety behaviors experiment (SBE) was not delivered in individual sessions. As reported in by Edwards and Kannan (2006), the version developed in Germany by Stangier, Heidenreich, Peitz, Lauterbach and Clark (1997) was found to be less effective than individual CTSP in a randomized controlled trial. Another version developed in Ireland by Bates (personal communication, 2005) has not been formally evaluated. There is no adequate data at this stage to compare the different versions. 
How the Case of Vumile Contributes to the Evidence Base for Cognitive Therapy

with Social Phobia as an Empirically Grounded Clinical Intervention

D.J.A. Edwards

Pragmatic Case Studies in Psychotherapy, http://pcsp.libraries.rutgers.edu

Volume 2, Module 1, Article 6, pp. 1-17, 02-17-06 [copyright by author]

Our small trial with only five completers does not really allow for a trustworthy estimate of an effect size. Although several effect size statistics have been developed for application to single cases, they are so diverse and yield such a range of values that they are difficult to interpret in relation to group effect size statistics (Parker, et al, 2005). However, our results suggest that our strategy of building a personal model of each client's case formulation over several sessions and employing interactive exercises to do this is worth considering for future versions of group CTSP since this strategy showed positive effects in engaging participants in the process of the therapy, in raising self-awareness and insight, and in building group cohesion.

The role of group cohesion relates to another point raised by Turk (2006). Our approach is entirely in line with her observation that "even when a treatment manual is used, successful treatment is characterized by an integration of the case conceptualization, the treatment techniques, the unique characteristics of the patient, and the therapeutic relationship." She therefore specifically asks for more information about the role of the therapeutic relationship in Vumile's treatment. In our version of group CTSP, participants have two sets of therapeutic relationships, the one with the group leaders, the other with other group members. Cohesion and mutual support between group members was deliberately fostered and made a significant contribution to Vumile's progress. Although not explicit in the narrative, it is fundamental to this kind of therapy for group leaders to establish themselves as credible mentors who offer participants a warm and empathic relationship (White \& Freeman, 2000). As the senior group therapist, I presented myself as authoritative, a person with expert knowledge who was offering guidance and direction based on scientific research. At the same time I showed myself able to understand and empathize with participants' predicaments and to help them articulate underlying cognitions and related emotions. The assistants presented themselves as students who were also learning about the process and who could engage honestly with the group, at times disclosing their own concerns and vulnerabilities. There were no obvious conflict situations between the group members and the team, and members appeared to respond well to our blend of authoritativeness, guidance and empathy.

Vumile himself responded well to the mentorship we offered and clearly experienced the technical aspects as credible even when he at times became discouraged. My own observation is that he formed less of a personal relationship with me than usually happens in individual therapy. This is not necessarily a disadvantage. A relationship with a group leader is in some ways less threatening than that with an individual therapist. In contrast to individual treatment, Vumile did not have to interact with us throughout the entire period of therapeutic contact. Much of the time he was observing others interacting with us or interacting with group members within the group or in the exercises in pairs. These aspects of the relationship with group leaders in cognitive-behavioral group therapy deserve more investigation.

Finally Turk (2006) asks whether we would propose any modifications to the treatment as a result of our program evaluation. Our project was a formative one. We did not design the full program at the outset and follow it rigidly from session to session. At the outset, we were not even sure how many sessions the program would take. We reviewed the pace at which we went through the steps of the Clark manual on a session by session basis, 
How the Case of Vumile Contributes to the Evidence Base for Cognitive Therapy

with Social Phobia as an Empirically Grounded Clinical Intervention

D.J.A. Edwards

Pragmatic Case Studies in Psychotherapy, http://pcsp.libraries.rutgers.edu

Volume 2, Module 1, Article 6, pp. 1-17, 02-17-06 [copyright by author]

and we planned the next session by integrating three concerns: (1) the need to build group cohesion, (2) the steps set out in the manual, and (3) the level of understanding and engagement with the material on the part of group members. The manual as set out in the appendix evolved from this process and could be used without modification. There are two modifications that could be considered when running it again. First, consideration should be given to the incorporation of new insights from research, especially on the role of imagery in social phobia, and the inclusion of a session on imagery rescripting. Second, consideration should be given to starting the safety behaviors experiment a session or two earlier: the impending University vacation played a role in our decision to delay it as long as we did.

\section{METHODOLOGICAL ASPECTS RELATED TO DATA COLLECTION}

Commentators also raised important questions about aspects of our research methodology. Several of them point to positive achievements in the way we set this up. For example, it is reassuring that S. Fishman (2006) concludes that we had anticipated what are now emerging as sound case study standards, especially since, as shown by Goodheart (2005) in her commentary on an earlier module of this journal, there is increasing recognition of the unique contribution of case studies within the wider project of gathering evidence related to best practice. However, Turk makes the valid criticism that it would have been better if the research interviews had been conducted by an independent party. Having members of the treatment team conduct the interviews creates the risk that the respondent will try to please the interviewer and the interviewer may unwittingly seek affirmation and be defensive about criticism. Unfortunately, we did not have the resources for this. At the same time there are disadvantages to having the research interviews conducted by an independent party since the participant may not trust that person, and so may disclose less, and the interviewer will be less familiar with the details of the therapy process and so may not be able to ask such indepth questions. In terms of "inside" interviewers not always pulling for positive outcomes, it is worth noting in Vumile's case that in the post-treatment interviews, the interviewer who knew Vumile would have been less surprised if Vumile had reported discouragement and relapse than she actually was by his accounts of active and effective engagement in behavioral experiments and by the sudden progress that he reported.

Turk (2006) also suggests that the study could have been improved by including an assessment of treatment adherence. The value of a comprehensive narrative is that it provides a resource for answering a range of different questions. Although we did not formally assess this aspect, there is considerable evidence that Vumile did engage with the treatment consistently throughout the program per se and also during the vacation break and after the treatment was over. A measure of treatment adherence could be of value for comparison with other cases or studies. However, qualitative analysis is able to provide a more than adequate answer to this question for a particular client.

This brings into focus the important methodological question about the relative significance of the evidence from qualitative data as compared to that from standardized measures. S. Fishman (2006) and Turk (2006) both raise the concern that we did not use some of the widely used standardized quantitative measures of social phobic thinking and 
How the Case of Vumile Contributes to the Evidence Base for Cognitive Therapy

with Social Phobia as an Empirically Grounded Clinical Intervention

D.J.A. Edwards

Pragmatic Case Studies in Psychotherapy, http://pcsp.libraries.rutgers.edu

Volume 2, Module 1, Article 6, pp. 1-17, 02-17-06 [copyright by author]

behavior in our work with Vumile and his group. As S. Fishman and Turk point out, the use of such measures would have facilitated comparison with data from other studies. This point is valid, and the fact that the measures were not employed was due to our inexperience and the fact that the opportunity to conduct the study arose unexpectedly and plans were developed rather quickly. However, S. Fishman is not accurate in claiming that the outcomes of treatment were not adequately operationalized, although this aspect was perhaps not made sufficiently explicit by Edwards and Kannan (2006). The scales used by Clark and colleagues in the development of their CTSP model measure quite specific aspects of social phobic thinking and behavior: cognitions commonly associated with social phobia (Social Cognitions Inventory); safety behaviors (Social Behavior Questionnaire); and anticipatory anxiety, self-focused=attention, and post-mortem worrying (Social Summary Rating). These aspects are specifically targeted in the CTSP program.

These points also bring into focus the question of how to address both nomothetic and idiographic approaches to designing data collection. The advantage of using standardized quantitative measures is that they can be applied to anyone who is similar to the standardization samples and that they allow for comparisons within and across studies. However the downside of standardization and quantification is often ignored (Edwards, Dattilio, \& Bromley, 2004). First the standardization sample may be rather narrow so that the number of real world people to whom it can be reliably applied is rather small. More important, however, is that standardized measures fall clearly at one end of the nomotheticidiographic continuum. They very usefully tap characteristics that can be identified in all people. Often these are rather broad and cannot portray unique or specialized aspects of an individual's life and experience.

To address this problem, Bilsbury and Richman (2002, p. 20) propose an idiographically oriented method of scaling which is particularly suited to the evaluation of formulation-driven treatment approaches. For each individual, a unique scale is developed around one or more "foci of therapeutic attention" (FOTAs). The scale is divided into four generic stages, from "4) "Frank illness with symptoms and dysfunction," to (3) "Response; a significant reduction in symptoms, crossing the diagnostic threshold. Subthreshold, residual symptoms are present," to (2) "Remission. Symptoms are largely controlled, symptom manifestations are within the range of the normal population. Also, there is functional improvement such as with minimal social/work impairment, " to (1) "Recovery but with disease vulnerability" (p. 21). Several levels can then be defined within each stage. This is done in close collaboration with the patient, whose phenomenological definition and understanding of the problem and whose goals for treatment serve as the basis for the scaling. Treatment can be evaluated on an ongoing basis by identifying what level patients are on each FOTA stage.

Bilsbury and Richman point out that

rather than trying to select the most suitable scales for measuring the patient's problems, the reverse occurs. The practitioner operationalizes the patient's concerns into qualitative ordinal levels that form a four-step gradient ranging from the stage of severe disorder to the stage of recovery (p. 19). 
How the Case of Vumile Contributes to the Evidence Base for Cognitive Therapy

with Social Phobia as an Empirically Grounded Clinical Intervention

D.J.A. Edwards

Pragmatic Case Studies in Psychotherapy, http://pcsp.libraries.rutgers.edu

Volume 2, Module 1, Article 6, pp. 1-17, 02-17-06 [copyright by author]

To illustrate their model, Billsbury and Richman provide a number of clinical examples of what their measurement model looks like for individual clients. Here is one of the examples as it spells out a problem of social anxiety for a specific client:

Level 4: Precarious. A prominent feeling of alert self-consciousness, as if in a spotlight, others (and myself) observing every move. Acutely aware that this distress is visible. Extremely sensitive to the likelihood of negative and hostile reactions from others, who have the power to hurt by possible rejection. Its next to impossible to converse with others because I don't have anything to say and because thoughts wheeling my head stop me from listening, and impede a normal conversation.

Level 3: On-guard alertness. Self-conscious in social interaction; alert to the possibility that others are observing my faults. Afraid of sounding foolish. Comparison with others vitiates my self-worth. I feel unworthy or inferior to another, then temper the angst by reminding myself of my own worth. Conscious of the negative impression I'm probably making on the other person. Unable to interact naturally, thinking of exactly what to say next, leading to a short, choppy style of conversation.

Level 2: Uncomfortable. Rather self-conscious that my faults are evident, and worried about what I should say. Although I'm not able to let myself go lest I sound foolish, I can listen, and explain myself at a push. Conversation flows, but with abruptions [sic].

Level 1: Natural. Not troubled by what others think of me, feeling an equal and relating well - putting out compliments. Transparent and spontaneous. Can say things that are well thought out, rather than self-consciously dwelling on other people's opinions of me, and the possibility of their negative reactions. I don't connect the opinions of others to my own worth and happiness, and am not driven to achieve for the sake of their admiration. Welcoming people's approaching without defensiveness. I realize that achievements and virtues do not necessarily inspire liking (p. 26-27).

S. Fishman (2006) and Turk (2006) both observe that clinicians do not necessarily adopt treatments shown to be effective in randomized controlled trials because of concerns about their generalization to a more complex patient population where co-morbidity is common. This problem could be addressed by giving greater emphasis to case formulation and the development of manuals that are flexible in this regard. Systematic case study research is an ideal way to document the application of manualized treatments proven effective in randomized control trials, to experiment with extensions and modifications to treatment that can address problems that arise and work with the unique details that characterize difficult cases. Because, within the overall task of building a body of evidence on which to base decisions about best practice, cases studies make their contribution at the idiographic end of the continuum, Bilsbury and Richman's approach to measurement is likely to be of particular value and it is a mistake to argue that standardized scales are superior simply because they have been standardized. They are, of course, useful for cross-study comparisons and can and should be employed where they are available and appropriate to the client's problem. However, it is more important to have scales that closely tap the particularities of the phenomenology and behavior of clients. The Clark measures are neither standardized nor individually scaled, but they were effective in tapping these kinds of details in our sample because they have been developed out of an in-depth examination of the psychological processes underlying social phobia. 
How the Case of Vumile Contributes to the Evidence Base for Cognitive Therapy

with Social Phobia as an Empirically Grounded Clinical Intervention

D.J.A. Edwards

Pragmatic Case Studies in Psychotherapy, http://pcsp.libraries.rutgers.edu

Volume 2, Module 1, Article 6, pp. 1-17, 02-17-06 [copyright by author]

There is a danger that standardization of scales is elevated beyond its station and the message is given that things do not exist if they are not measured by such scales. After all, Vumile's goals for therapy were clear. He wanted to be able to interact freely with people, meet and chat to young women and in due course start dating. The narrative documents his steady progress towards achieving those goals. The data from scales provided invaluable information about some of the psychological and behavioral changes that took place as part of this process, but Vumile's ongoing accounts in sessions and research interviews of his behavioral experiments and new experiences are just as good evidence that meaningful change was taking place. While critics may point to the bias inherent in self-reported progress of this sort, bias is no less a problem for self-report scales even where they have been standardized since individual respondents vary in their interpretation of items and their susceptibility to biases such as extreme responding, central tendency and social desirability.

\section{METHODOLOGICAL ASPECTS RELATED TO DATA INTERPRETATION}

In interpreting the Vumile study, Edwards and Kannan (2006) concluded first, that Vumile's projection of pitying and disdainful facial expressions on to others was an important factor maintaining his social phobia; and second, that his rapid progress in the weeks after the end of the program was due to his having addressed it with his ethnographic experiment in which he systematically observed women's faces. S. Fishman (2006) seems skeptical when he offers a "more parsimonious explanation" in terms of "consolidation of gains." This seems to be a revival of the classic debate in learning theory about one-trial versus incremental learning. It raises important questions about how we seek to explain psychological change. Cognitive science is developing a more and more differentiated understanding of how a variety of factors interact to give rise to the momentary stream of organismic experience with its multiplicity of components involving emotion, cognition and behavior. In parallel with this, cognitive models of psychopathology are also becoming more detailed. This means that we can advance more and more differentiated hypotheses about the sources of specific problems and the mechanisms of change. In contrast to randomized control trials, which can make little contribution to this area, carefully designed experimental studies and case studies provide means for investigating and testing such hypotheses and so advancing clinical theory (Edwards et al. 2004).

The interpretation of the data is the critical final step in a case-based methodology. The value of a well designed case study is that it does provide evidence in favor of or against specific theoretical propositions. Critics often argue that one cannot generalize from case study while assuming that there are fewer problems in generalizing from studies which use statistical comparisons of means of matched or randomized groups. The data from a case can seldom prove a particular point (no data from any study can do this taken alone). However, it can provide evidence which, when taken in conjunction with data from other cases or from experimental studies, can contribute to an accumulating weight of evidence in favor of or against particular interpretations or theoretical positions. In practice any methodology is designed to enhance the researcher's ability to draw conclusions, but usually there is a trade off. For example, experimental manipulations often sacrifice external validity, and group comparisons ignore the range of individual differences within each group. Case studies are 
How the Case of Vumile Contributes to the Evidence Base for Cognitive Therapy

with Social Phobia as an Empirically Grounded Clinical Intervention

D.J.A. Edwards

Pragmatic Case Studies in Psychotherapy, http://pcsp.libraries.rutgers.edu

Volume 2, Module 1, Article 6, pp. 1-17, 02-17-06 [copyright by author]

robust with respect to each of these, but may be weak on internal validity (providing evidence for causal relationships). However, a case study that contains a rich body of qualitative data may provide the kind of evidence for causal relationships within the case of a kind that no other kind of method can offer. That is why they are unmatched for generating and testing hypotheses about the interaction of psychological processes, the kinds of interactions that are central to the process of case formulation for psychotherapy.

From this perspective, what can be concluded about the factors that led to Vumile's progress? First, S. Fishman's explanation of Vumile's progress in terms of consolidation of gains is not so much an alternative as a complementary explanation. The narrative demonstrates that several factors were at work in maintaining the social phobia and these were addressed cumulatively throughout the course of the treatment. However, in spite of this there was remarkably little reduction on the variables measured by the self-report scales. The results on these scales do not support an interpretation in terms of a cumulative effect. While it seems probable that the behavioral observation experiment alone might have had a more limited impact if introduced much earlier, when Vumile implemented it, it had what has been called a "slam-bang" effect on the outcome measures. This colorful term refers to a sudden marked change in an outcome variable in response to an intervention where there is a reasonable baseline and other interventions have failed. This provides very strong evidence for a causal effect (Kazdin, 1981). Of course, alternative explanations must be considered. Did something else happen to cause the sudden progress? In two lengthy post-treatment interviews no such extraneous factors could be found. Given the researcher's relationship with Vumile as it had built up over the course of program, it is improbable that Vumile would not have mentioned it if, for example, he had fallen in love or started taking drugs that massively reduced his anxiety. Neither of these explanations fit with the account Vumile actually gave, which was, in itself, coherent and makes theoretical sense.

Turk (2006) challenges Edwards and Kannan's (2006) conclusion that the study supports the proposition that "cognitive change is critical for symptom reduction." As she points out, there has been considerable debate about the significance of cognitive change in recovery from social phobia. She also seems to imply that case studies cannot provide evidence for conclusions about psychological process or contribute anything evidential to this debate. She remarks that "it is impossible to definitively say that Vumile would not have responded equally well to a treatment consisting of exposure exercises accompanied by a habituation rationale." This conclusion underestimates the role of the case study within the overall process of building an evidence base for practice. It is precisely the kind of evidence often seen by clinicians in practice that gave rise to the view that cognitive change is critical. This is the foundation of the Clark and Wells cognitive model. One value of the Vumile study is that it provides systematic documentation of this kind of process and therefore inserts it into the evidence base in a way that cannot be dismissed as "anecdotal."

Vumile's case demonstrates a range of strengths in the Clark (1997) treatment approach. The flexibility of the treatment approach, which was discussed above and commended by Turk, is built on its inclusion of multiple strategies for change. These strategies are not randomly selected, but incorporated on the basis of a differentiated model of the factors that maintain social phobia. A formulation in terms of exposure and habituation offers much less to the clinician in terms of devising an individualized treatment plan. Turk is 
How the Case of Vumile Contributes to the Evidence Base for Cognitive Therapy

with Social Phobia as an Empirically Grounded Clinical Intervention

D.J.A. Edwards

Pragmatic Case Studies in Psychotherapy, http://pcsp.libraries.rutgers.edu

Volume 2, Module 1, Article 6, pp. 1-17, 02-17-06 [copyright by author]

right that we cannot be certain how Vumile would have responded to a treatment based on exposure with a habituation rationale. However it seems unlikely that such a limited conceptualization would have led to Vumile conducting the critical behavioral experiment which, on the basis of sound evidence, seems to have been responsible for significant change. The Vumile study was planned early in 2000. Since then, the evidence base for claims about the significance of cognitive change has advanced considerably beyond the informal clinical observations that provided its initial impetus. The accumulation of evidence from diverse sources using complementary research methods is fundamental to the development of what Salkovskis (2002) calls "empirically grounded clinical interventions." In the development of CTSP, published studies now include (a) case studies (Bates \& Clark, 1998; Edwards, Henwood, \& Kannan, 2003; Edwards \& Kannan, 2006; Wells \& Papageorgiou, 1997); (b) experimental studies (e. g. Harvey, Clark, Ehlers, \& Rapee, 2000; McManus, Clark, \& Hackmann, 2000; McManus et al., 2005; Stopa \& Clark, 2000); (c) qualitative survey studies (Hackmann, Clark, \& McManus, 2000); and (d) Clark et al.'s (2005) RCT, referred to above, in which the effect size for CTSP was considerably higher than that for exposure and applied relaxation. Edwards and Kannan's (2006) conclusion that the Vumile case provides evidence for the significance of cognitive change should be not be interpreted to mean that it demonstrates this with certainty. However, it is a claim that it adds its weight to an accumulating body of diverse evidence that is pointing ever more strongly in that direction.

As the title of Edwards and Kannan's (2006) paper suggests, the case provides evidence for a central principle of cognitive therapy: the importance of identifying and targeting idiosyncratic cognitive processes that maintain problematic behaviors and distressing emotional states. It documents such processes in a particular case and shows how the identification of quite a specific process can be critical for outcome. As Bilsbury and Richman (2002, p. 20) observe, "patients with similar diagnoses have diverse needs for treatment." The conclusion is not of course that the particular process that was identified in Vumile will be found in all individuals with social phobia. However, it would be surprising if it was not found in some other cases. This is why case studies have such an important role to play within the overall project of building scientific knowledge. We can build up a body of specific observations and understand the general principles which govern the relationships between them, but these processes and relationships will be uniquely configured in individuals. Without the close study of individual cases it is not possible to develop useful applied knowledge that can provide a basis for in-depth assessment and flexible and responsive treatment planning for individuals who present with significant psychological distress.

\section{REFERENCES}

Allport, G. W. (1963). Pattern and growth in personality. New York: Holt, Rinehart and Winston.

Bandura, A. (1977). Social learning theory. Englewood Cliffs, NJ: Prentice-Hall.

Bates, A. \& Clark, D. M. (1998). A new cognitive treatment for social phobia: A single case study. Journal of Cognitive Psychotherapy, 12, 289-302.

Beck, A. T., Rush, A. J., Shaw, B. F., \& Emery, G. (1979). Cognitive therapy of depression. New York: John Wiley. 
How the Case of Vumile Contributes to the Evidence Base for Cognitive Therapy

with Social Phobia as an Empirically Grounded Clinical Intervention

D.J.A. Edwards

Pragmatic Case Studies in Psychotherapy, http://pcsp.libraries.rutgers.edu

Volume 2, Module 1, Article 6, pp. 1-17, 02-17-06 [copyright by author]

Bilsbury, C. D. \& Richman, A. (2002). A staging approach to measuring patient-centred subjective outcomes. Acta Psychiatrica Scandinavica, 196 (Suppl. 414), 5-40.

Clark, D. M. (1997). Cognitive therapy for social phobia: Some notes for therapists. Oxford: University of Oxford, Department of Psychiatry.

Davison, G. C. (2005). Reviewer's report on "Identifying and targeting idiosyncratic cognitive processes in social phobia: The case of Vumile" for Pragmatic Case Studies in Psychotherapy.

Eagle, G. T. (2004). Therapy at the cultural interface: implications of African cosmology for traumatic stress intervention. Psychology in Society, 30, 1-22.

Edwards, D. J. A., Dattilio, F., \& Bromley, D. B. (2004). Developing evidence-based practice: The role of case-based research. Professional Psychology: Research and Practice, 35, 589-597.

Edwards, D. J. A., Henwood, J., \& Kannan, S. (2003). Cognitive therapy for social phobia: The human face of cognitive science. Alternation, 10 (2), 122-150.

Edwards, D. J. A. \& Kannan, S. (2006). Identifying and targeting idiosyncratic cognitive processes in group therapy for social phobia: The case of Vumile. Pragmatic Case Studies in Psychotherapy [Online], Vol. 2(1), Article 1. Available: http://hdl.rutgers.edu/1782.1/pcsp_journal

Ehlers, A., Clark, D. M., Hackmann, A., McManus, F., \& Fennell, M. (2005). Cognitive therapy for post-traumatic stress disorder: development and evaluation. Behaviour Research and Therapy, 43, 413-431.

Ensink, K. \& Robertson, B. A. (1996). Indigenous categories of distress and dysfunction in South African Xhosa children and adolescents as described by indigenous healers. Transcultural Psychiatric Research Review, 33, 137-172.

Fishman, D. B. (2005). Editor's Introduction to PCSP - From Single Case to Database: A New Method for Enhancing Psychotherapy Practice. Pragmatic Case Studies in Psychotherapy [Online], Vol. 1(1), Article 2. Available: http://hdl.rutgers.edu/1782.1/pcsp journal

Fishman, S. T. (2006). Commentary on Identifying and targeting idiosyncratic cognitive processes in group therapy for social phobia: The case of Vumile. Pragmatic Case Studies in Psychotherapy [Online], Vol. 2(1), Article 4. Available: http://hdl.rutgers.edu/1782.1/pcsp journal

Goodheart, C. D. (2005). Placing psychotherapy case studies within the framework of the APA evidence-based practice in psychology (EBPP) model. Pragmatic Case Studies in Psychotherapy [Online], Vol. 1(3), Article 2. Available: http://hdl.rutgers.edu/1782.1/pcsp_journal

Hackmann, A., Clark, D. M., \& McManus, F. (2000). Recurrent images and early memories in social phobia. Behaviour Research and Therapy, 38, 601-610.

Harvey, A. F., Borkovec, T. D., Hayes, S. C., Persons, J. B., \& Wilson, G T. (2005, Nov. 19). Psychological processes across psychological disorders: Implications of transdiagnostic approaches for therapy, research, and treatment. Panel discussion presented at the annual convention of the Association for Behavioral and Cognitive Therapies, Washington, D.C.

Harvey, A. G., Clark, D. M., Ehlers, A., \& Rapee, R. M. (2000). Social anxiety and selfimpression: Cognitive preparation enhances the beneficial effects of video feedback following a stressful social task. Behaviour Research and Therapy, 38, 1183-1192. 
How the Case of Vumile Contributes to the Evidence Base for Cognitive Therapy

with Social Phobia as an Empirically Grounded Clinical Intervention

D.J.A. Edwards

Pragmatic Case Studies in Psychotherapy, http://pcsp.libraries.rutgers.edu

Volume 2, Module 1, Article 6, pp. 1-17, 02-17-06 [copyright by author]

Harvey, A. G., Watkins, E., Mansell, W. \& Shafran, W. (2004), Cognitive behavioural processes across psychological disorders: A transdiagnostic approach to research and treatment. New York: Oxford University Press.

Kazdin, A. E. (1981). Drawing valid inferences from case studies. Journal of Consulting and Clinical Psychology, 49, 183-192.

Marlatt, G. A. \& Gordon, J. R. (1984). Relapse prevention: Maintenance strategies in addictive behavior. New York: Guilford.

McManus, F., Clark, D. M., Grey, N., Wild, J., Hirsch, C., Fennell, M. et al. (2005). An investigation of the efficacy of two of the components of cognitive therapy for social phobia. Paper presented at the 5th International Congress of Cognitive Psychotherapy, Götenborg, Sweden. June.

McManus, F., Clark, D. M., \& Hackmann, A. (2000). Specificity of cognitive biases in social phobia and their role in recovery. Behavioural and Cognitive Psychotherapy, 28, 201209.

Meichenbaum, D. (1977). Cognitive-behavior modification: An integrative approach. New York: Plenum.

Messer, S. B. (2004). Evidence-based practice: Beyond empirically supported treatments. Professional Psychology: Research and Practice, 35, 580-588.

Parker, R. I., Brossart, D. F., Vannest, K. J., Long, J. R., De-Alba, R. G., Baugh, F. G. et al. (2005). Effect sizes in single case research: How large is large? School Psychology Review, 34, 116-132.

Persons, J.B. (1989). Cognitive therapy in practice: A case formulation approach. New York: W.W. Norton.

Persons, J. B. \& Tomkins, M. A. (1997). Cognitive-behavioral case formulation. In T. D. Eells (Ed.), Handbook of psychotherapy case formulation (pp. 314-339). New York: Guilford.

Petronko, M. R. (2005). Towards formalizing a very promising treatment. Pragmatic Case Studies in Psychotherapy [Online], Vol. 1(2), Article 3. Available: http://hdl.rutgers.edu/1782.1/pcsp_journal

Salkovskis, P. M. (2002). Empirically grounded clinical interventions: Cognitive-behavioral therapy progresses through a multi-dimensional approach to clinical science. Behavioural and Cognitive Psychotherapy, 30, 1-10.

Sanderson, W. C. (2006). Evaluating adherence and flexibility in the use of a manual in clinical practice. Pragmatic Case Studies in Psychotherapy [Online], Vol. 2(1), Article 3. Available: http://hdl.rutgers.edu/1782.1/pcsp_journal

Smucker, M. R. \& Dancu, C. V. (1999). Cognitive-behavioral treatment of adult survivors of childhood trauma: Imagery rescripting and reprocessing. Northvale, NJ: Jason Aronson.

Stangier, U., Heidenreich, T., Peitz, M., Lauterbach, W., \& Clark, D. M. (2003). Cognitive therapy for social phobia: Individual versus group treatment. Behaviour Research and Therapy, 41, 991-1007.

Stopa, L. \& Clark, D. M. (2000). Social phobia and interpretation of social events. Behaviour Research and Therapy, 38, 273-283.

Thwaites, R. \& Freeston, M. (2005). Safety-seeking behaviours: Fact or function? How can we clinically differentiate safety behaviours and adaptive coping strategies across anxiety disorders. Behavioural and Cognitive Psychotherapy, 33, 177-188. 
with Social Phobia as an Empirically Grounded Clinical Intervention

D.J.A. Edwards

Pragmatic Case Studies in Psychotherapy, http://pcsp.libraries.rutgers.edu

Volume 2, Module 1, Article 6, pp. 1-17, 02-17-06 [copyright by author]

Turk, C. L. (2006). Breathing life into a manual and theoretical model. Pragmatic Case Studies in Psychotherapy [Online], Vol. 2(1), Article 5. Available: http://hdl.rutgers.edu/1782.1/pcsp_journal

Wampold, B. E. \& Bhati, K. S. (2004). Attending to omissions: A historical examination of evidence-based practice movements. Professional Psychology: Research and Practice, 35, 563-570.

Wells, A. \& Papageorgiou, C. (1997). Brief cognitive therapy for social phobia: A case series. Behaviour Research and Therapy, 39, 713-720.

White, J. R. \& Freeman.A. (2000). Cognitive-behavioral group therapy for specific problems and populations. Washington, DC: American Psychological Association.

Wild, J., Hackmann, A., Clark, D. M., \& Ehlers, A. (2005). Updating social trauma memories in social phobia: Impact on imagery and beliefs. Paper presented at the 5th International Congress of Cognitive Psychotherapy, Götenborg, Sweden. June. 